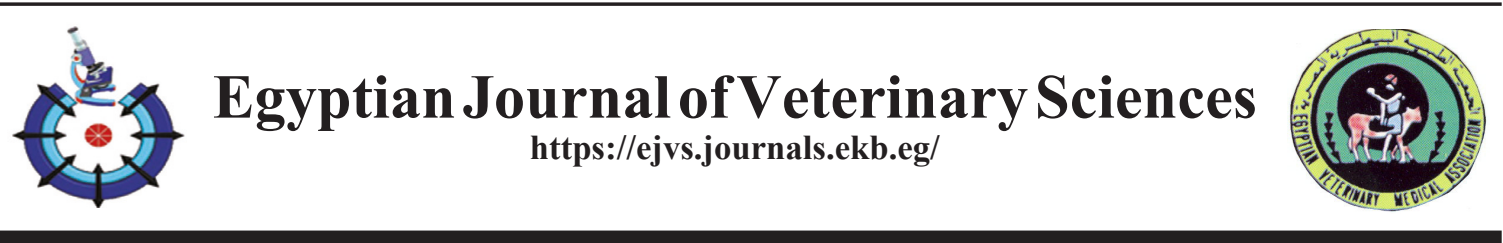

\title{
Comparative Evaluation The Role of Venous and Peritoneal Autograft as Bioscaffold for Repairing Achilles Tendon Defect in Dogs
}

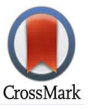

\author{
Asmaa H. Allawi ${ }^{1}$ and L. M. Alkattan ${ }^{2}$ \\ ${ }^{1,2}$ Department of Surgery and Theriogenology, College of Veterinary Medicine, \\ University of Mosul, Iraq.
}

$\mathbf{T}$

HE STUDY was conducted on eighteen healthy dogs, which were allocated into three equal groups (six dogs each). In the first treatment, the hind limbs were prepared at the calcaneus region where Achilles' tendon was sharply incised, sutured with Kessler method, and immobilized with gypsona. The second treatment included the using of a peritoneum graft, while the third treatment utilized the venous autograft. Following surgery, all animals were inspected clinically, grossly and histopathologically for two months. Results of the first treatment exhibited adhesion and inflammatory reaction after one and two months of surgery. Histopathological examination revealed the organization of collagen fibers and mild inflammatory reaction after two months of surgery. The second treatment exhibited complete healing and the animal showed normal activities without any impairment on leg function. Grossly, a mild degree of adhesion was determined after two months of surgery. Histopathological examination exhibited complete granulation tissue formation with the slightest degree of fibroblast formation at 60 days. In the third treatment, there was an inflammatory reaction with moderate adhesion at one month of surgery. However, after 60 days post operation, the tendon restored the normal anatomical feature. In conclusion, unlike other treatments, results obtained from the using of peritoneal graft for reconstruction tendon defect was with the most convincing and efficient outcomes. The findings reported here shed a new light on treating of the defective tendon.

Keywords: Achilles tendon repair, Peritoneal, Venous, Autograft, Dogs.

\section{Introduction}

Tendons are a specialized form of connective tissue responsible for transmitting of mechanical forces from skeletal muscle to bone, stabilizing joints and acting as a shock absorber with unique ability to glide through the surrounding tissue [1]. Tendon defects are the most clinical issue for orthopedic surgeons. Thus, the present study intended to examine the efficacy of using three different surgical methods to repair the defective tendon. Unlike other types of connective tissue, such as bones, injured tendon requires a prolonged time for healing due to the insufficient or low blood supply [2]. Repairing of Achilles tendon aims to improve tendon healing and rehabilitation function of the involved area of the joint. Several surgical interventions have been described for reconstructing of the impaired tendon. For instance, tenorrhaphy is one of these methods where various non-absorbable suture materials are using accompanied with a locking loop or continuous cruciate [3]. In addition, several biomaterial substances were used, such as semi-tendinous muscle [4], synthetic mesh graft [5] or G-90 growth factor [6]. Furthermore, to improve and prompt the healing process of the injured Achilles tendon, low-level laser therapy was applied [7]. The healing process of the tendon is very complex, indecisive and varies widely depending on the severity of the trauma, treatment procedure and at the interval time between trauma and treatment. Postoperative

Corresponding author: Alkattan, Layth Mahmoud e-mail. laythalkattan@yahoo.com, Tel. 09647701631455

DOI. 10.21608/ejvs.2019.7794.1063

(Received 30/01/2019; accepted 10/06/2019)

C2019 National Information and Documentation Centre (NIDOC) 
complications are usual, which mainly occur due to the low vascularization of the tendon and the process of healing tends to cause adhesion with the surrounding tissues causing a restricted mobility $[8,9]$. However, several materials have been utilized to improve the healing process of the injured tendon, such as using of omental flap, butyric acid, adipose mesenchymal stem cells, artery flap platelet-rich plasma, autologous venous grafting, and this graft was used to promote healing and reduce the incidence of adhesion [10,11,29]. A recent review described different approaches of utilizing a bioactive scaffolds regeneration of the damaged tissue in bones and ligaments [12]. Treatment of the injured tendon with surgical suturing of the healthy ends together with another type of tissues needs to be protected with external support after surgery to prevent excessive weight bearing by healing tendon [13]. Although, many suture materials were used to repair the defective Achilles tendon; however, suturing with polyester approved its efficiency in tendon healing [14]. The aim of this study to determine the role of venous and peritoneal autograft as bioscaffold for reconstruction of Achilles tendon in dogs.

\section{Materials and Methods}

Achilles tendon of eighteen healthy dogs of both sexes were utilized .The animals were allocated into three equal groups, where each group included six dogs. Animals were feed, housed under the same conditions, and were subjected to aseptic pre-surgical protocol. Animals were anesthetized with the same protocol of anesthesia consisted of $10 \%$ Ketamine (Rotexmedica, Germany) $10 \mathrm{mg} / \mathrm{Kg}$ BW and 2\% Xylazine (Interchemie, Holland.) $5 \mathrm{mg} / \mathrm{Kg}$ BW[30] . In the control first group, the hind limb was prepared at the calcaneus region, and Achilles tendon was sharply transected. The tendon ends were isolated from the surrounding tissues and sutured using Kessler method with silk suture material (No 2 ), and the site of operation fixed with gypsona. The peritoneal graft second group, animals were also prepared and treated as the first group, except peritoneum patch, harvested surgically from same animals $3 \mathrm{~cm}$ as square pieces were utilized (Fig. 1). The tendon was wrapped with this patch and was firmly fixed to restrict its mobility. Finally, the skin sutured with simple interrupted technique and the site of operation was supported with gypsona. Similar preoperative surgical preparations were followed in the venous autograft third group; however, the jugular vein was utilized to repair the induced injury in the tendon. The vein was double-ligated and bluntly dissected out and extra surrounding tissues were removed. The harvested venous autograft (approximately $3 \mathrm{~cm}$ long) was then transferred into a normal saline solution containing 10\% gentamicin. The vein (3 cm long) was harvested surgically from the jugular region. The harvested vein was inverted and immersed in the normal saline solution contained $10 \%$ gentamicin. The venous autograft gently inserted through the two ends of the sutured tendon so, the sutured tendon was completely wrapped with the venous graft then this graft firmly sutured with tendon at two ends restrict movement of graft (Figs1-2).The tendon was wrapped with this graft and was fixed firmly to restrict movement (Figs1-2). The skin sutured and the site of operation fixed with gypsona , Flunixin ( Flumequin. Turky )at $1 \mathrm{mg}$ $\checkmark \mathrm{kg}$ bwt was used to control pain. In all groups, animals were inspected clinically and grossly ( macroscopic examination, the findings were recorded as degree of adhesions, inflammatory signs during a periods 15,30 and 60 days of treatment two animals of each periods ) on a daily

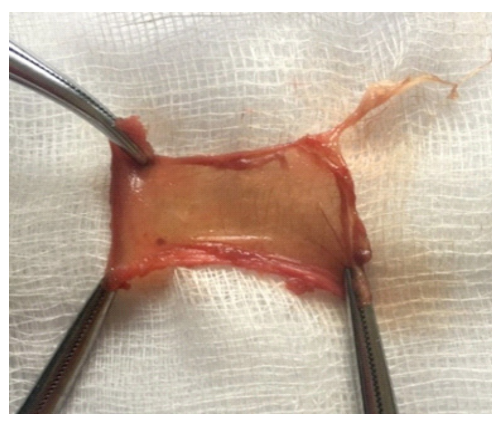

Fig. 1. An example of peritoneum graft harvested surgically.

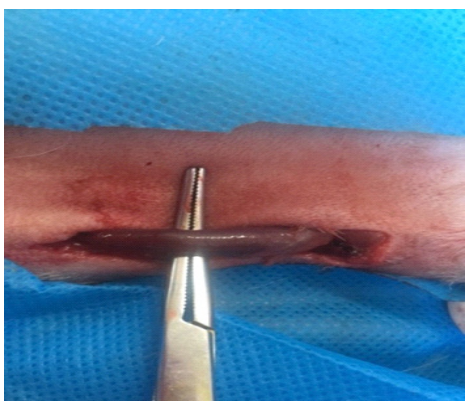

Fig. 2. Preparation of the jugular vein for harvesting vein graft.

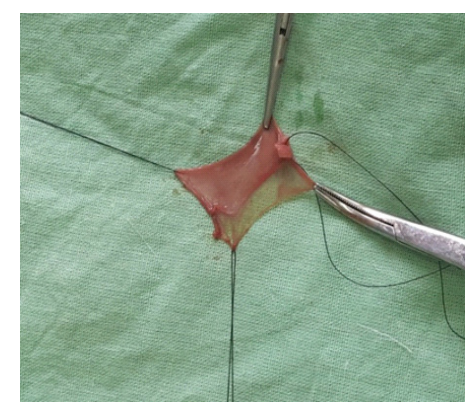

Fig. 3. Harvested vein's graft.

Egypt. J. Vet. Sci. Vol. 50, No. 2 (2019) 
basis . For histopathological examination, biopsies were collected aseptically from the junction of normal and treated tendon after 15,30,60 days of surgery (two animals for each periods) 2 weeks, one and 2 months of surgery. Biopsies were fixed in $10 \%$ neutral buffered formalin for 72 hours and tissue preparation proceeded as described by Luna ,1968[15]. Tissue sections were stained with Harris hematoxylin and eosin [16]. Later, the stained slides were examined at 40X, 100X, and $400 \mathrm{X}$ using light microscopy.

\section{$\underline{\text { Results }}$}

In the first group, animals manifested restlessness and were hardly using the treated leg, especially during flexing and dragging. These signs of difficulties were subsided during the first week and the animal's status was progressively improved. Clinically, all operative dogs were usually using the affected limbs during after two months of surgery where their motility appeared normal. Grossly, there were several noticeable healing defects including adhesions between the tendon and adjust tissue during the first month; this adhesion restricts the movement of the tendon. In addition, the presence of inflammatory reactions accompanied by incomplete healing (Fig 4). Two months post-surgery, there were sever adhesion between the treated tendons and adjust tissue, less inflammatory reaction with complete healing (Fig. 5). In the first group, histopathological examination revealed infiltration of mononuclear inflammatory cells, less number of fibroblast count and the presence of dense collagen fiber (Fig. 6). After 60 days, there were mature connective tissue at the healing region, organized collagen fibers, low number of fibroblast and mild inflammatory

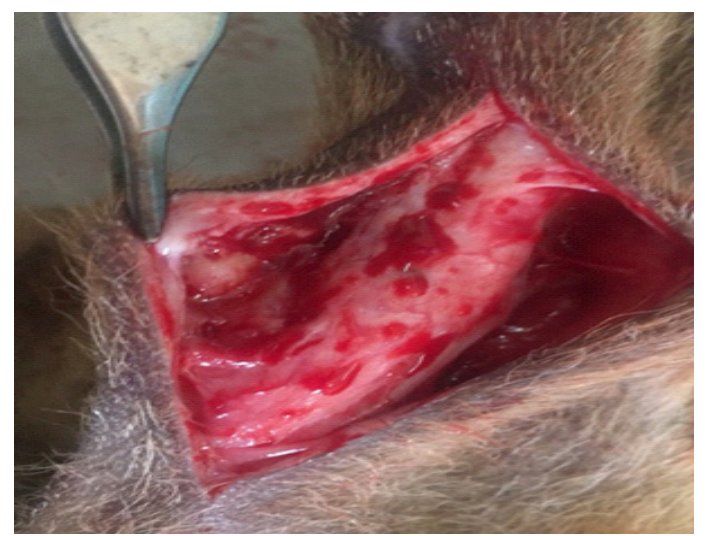

Fig. 4. Control group, Achilles tendon after a month of surgery. Indicating adhesion between the tendon and adjust tissue and an inflammatory reaction with incomplete healing. reaction (Fig. 7). In the second group, there was an improvement in the animal health status during the first two weeks where animals walked normally without any impairment in leg function. However, gross examination revealed the presence of a mild swelling at the site of operation without any sign of the inflammatory reaction. During the first 15 days of surgery, a moderate adhesion was notifying between the peritoneum patch and the surrounding tissues. Later, these adhesions were subsided (Figure 8) and only mild adhesions were present after 30 days of surgery (Fig 9). Interestingly, after 60 days, there were no inflammatory reactions at the site of operation and adhesions were subsided. Throughout this period, animals expressed normal activities and complete healing occurs (Fig. 10). The main histopathological feature after 30 days of treatment was manifested by an increased intensity of eosinophilic collagen fibers staining, low amount of fibroblast and edema between fibers and congestion of capillary vessels (Fig 11). Examination after 60 days of treatment revealed complete granulation tissue formation, low amount of fibroblast and congestion of capillary vessels (Fig 12). In the third group, inflammatory reaction and moderate adhesion were determined after 30 days of surgery (Fig 13). However, at 60 days, the inflammatory reaction was subsided and the tendon restored the normal anatomical feature (Fig 14). Histologically, at 30 days postoperatively, there was dense mature eosinophilic collagen fiber, low count of fibroblast and congestion of capillary vessels (Fig 15). After 60 days, the histopathological examination showed that collagen fibers were more organized, edema between collagen fibers without any evidence of inflammatory reaction (Fig 16)

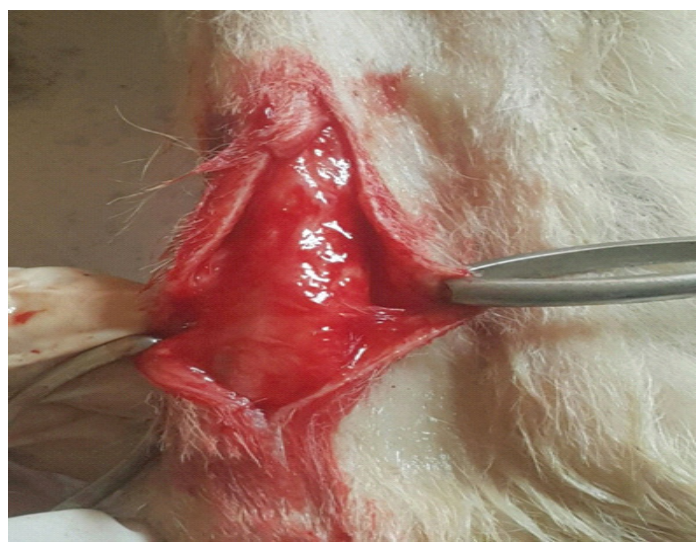

Fig. 5. Control group, Achilles tendon two months post-surgery. Indicating sever adhesion between the tendon and adjust tissue and mild inflammatory reaction with complete healing.

Egypt. J. Vet. Sci. Vol. 50, No. 2 (2019) 


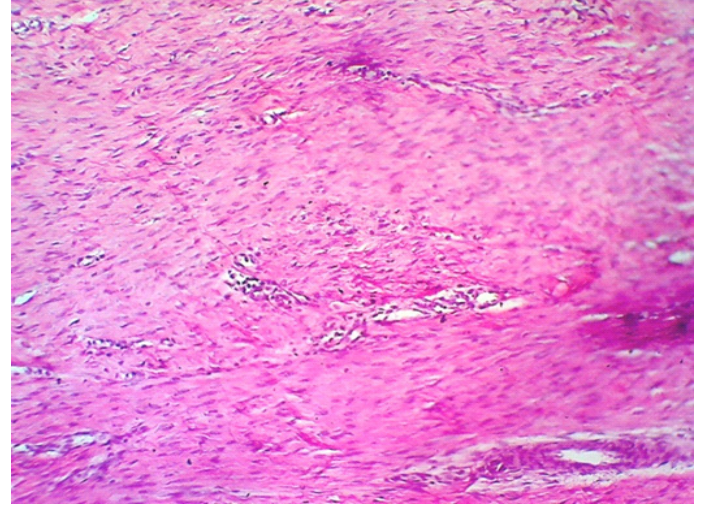

Fig.6. Control group, histological section a month post- surgery. Indicating a massive infiltration of mononuclear inflammatory cells, less number of fibroblast and dense collagen fiber, $H \& E$, 100x.

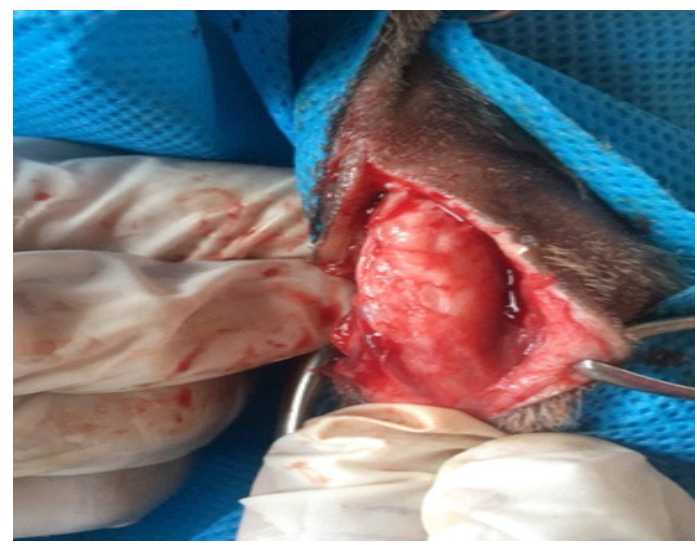

Fig. 8. Achilles tendon treated by the peritoneum graft, 15 days post-surgery. Indicating a moderate adhesion

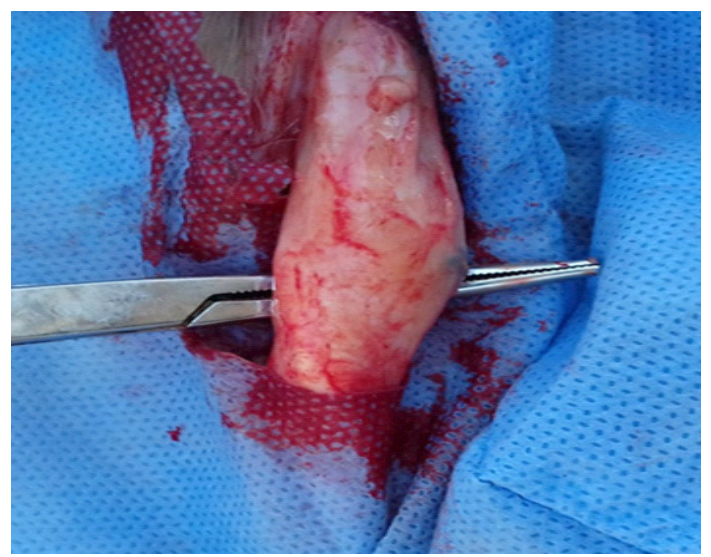

Fig. 10. Achilles tendon after two months manifesting no adhesion and the peritoneum graft subsided completely.

Egypt. J. Vet. Sci. Vol. 50, No. 2 (2019)

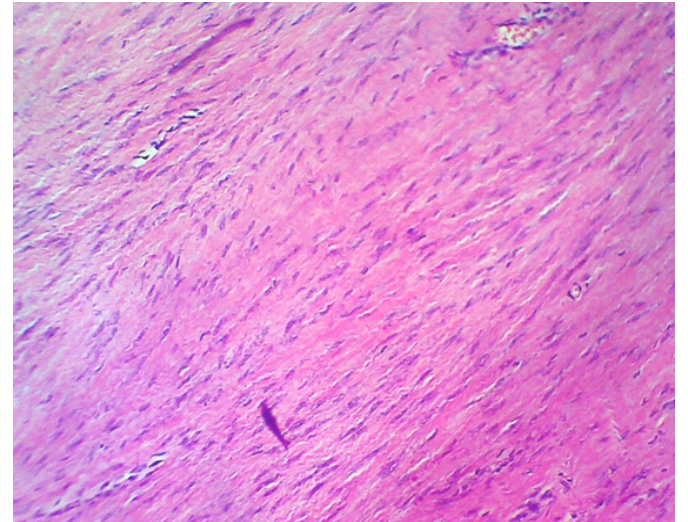

Fig. 7. Control group, a histological section of the healing region, two months post-surgery. Indicating the presence of mature connective tissue at the healing region manifesting by organized of collagen fiber, a low number of fibroblast and mild inflammatory reaction. H\&E 100x.

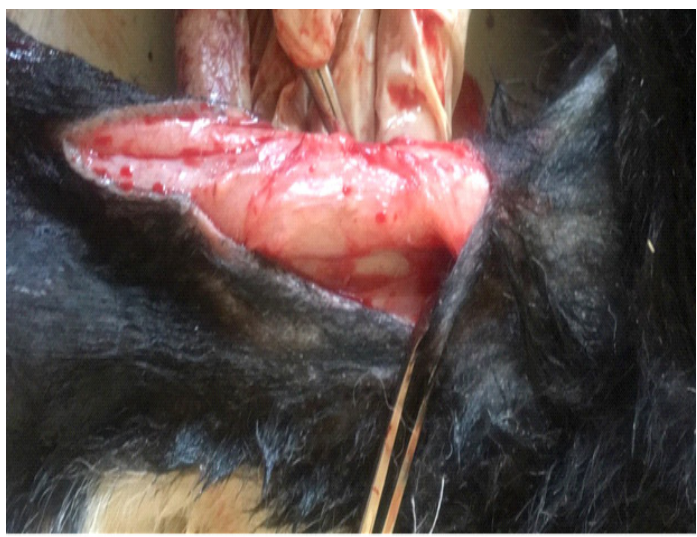

Fig. 9. Achilles tendon treated with the peritoneum graft, 30 days post-surgery. Indicating the presence of a mild adhesion.

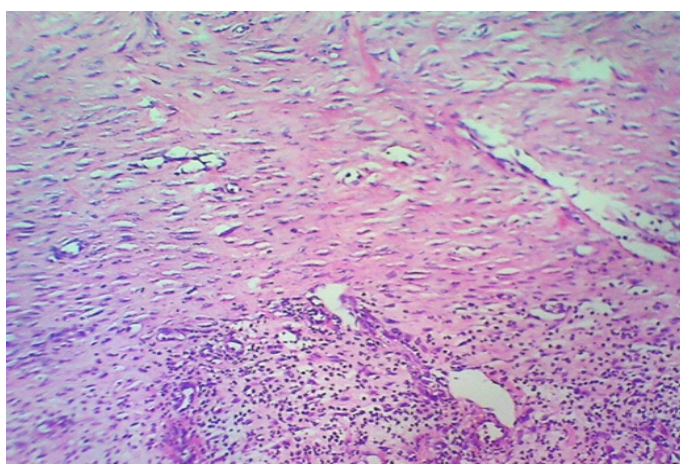

Fig. 11. Histological section of tendon healing in the second group, a month post-surgery. Intense eosin staining manifested by increased eosinophilic collagen fibers, low amount of fibroblast and edema between fibrous fibers, and congestion of capillary vessels. H\&E, 100x. 


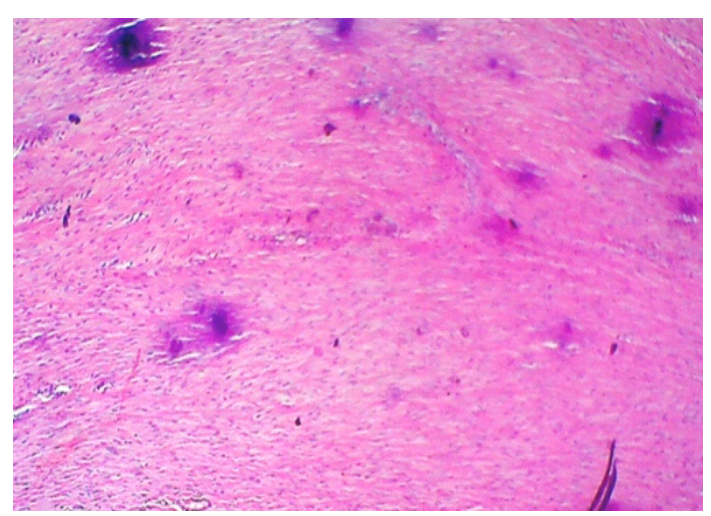

Fig. 12. Histological section of tendon healing in the 2nd group, two months post-surgery. There is a complete granulation tissue formation, low amount of fibroblast and congestion of capillary vessels. $H \& E$, 100x.

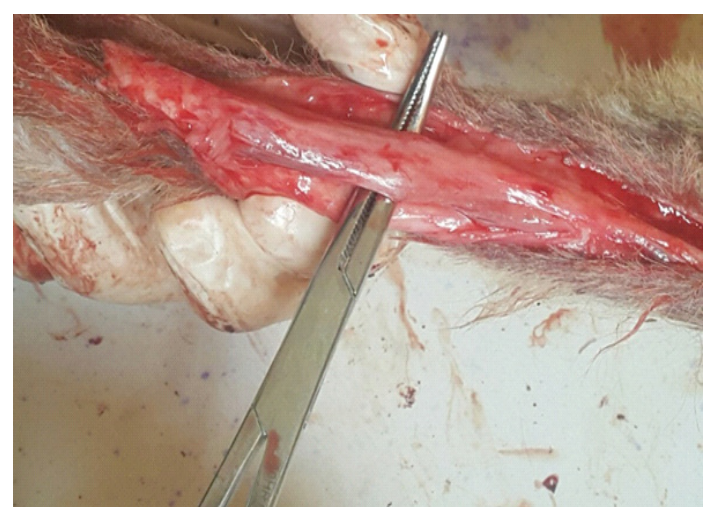

Fig. 14. Achilles tendon at 60 days post-surgery in the third group. The inflammatory reaction was subsided and the tendon restored the normal anatomical feature indicating the absence of adhesion.

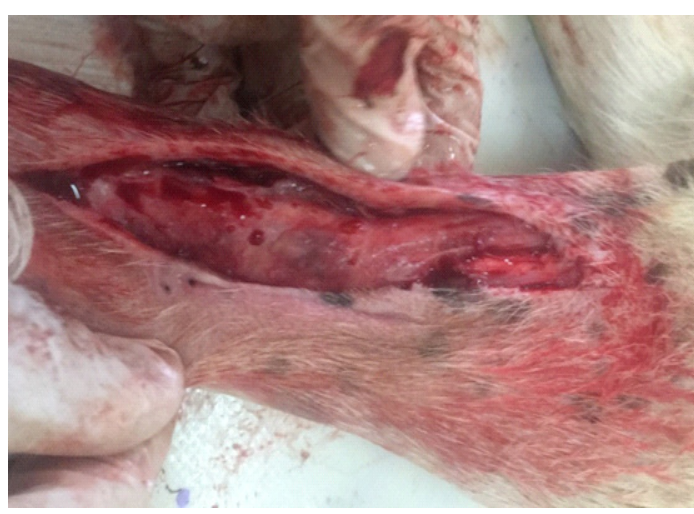

Fig. 13. Achilles tendon at 30 days post-surgery in the third group. Indicating an inflammatory reaction, moderate adhesion.

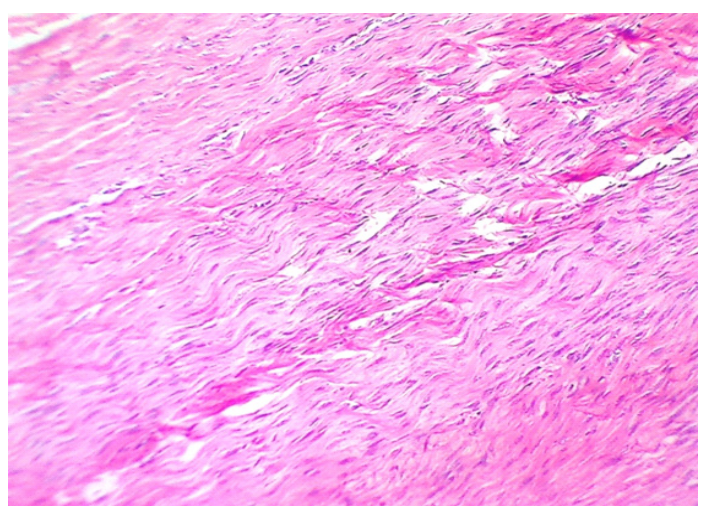

Fig. 15. Histological section of tendon healing in the 3rd group, a month post-surgery. There was dense mature eosinophilic collagen fiber, a low amount of fibroblast and congestion of capillary vessels. H\&E, 10(100)X.

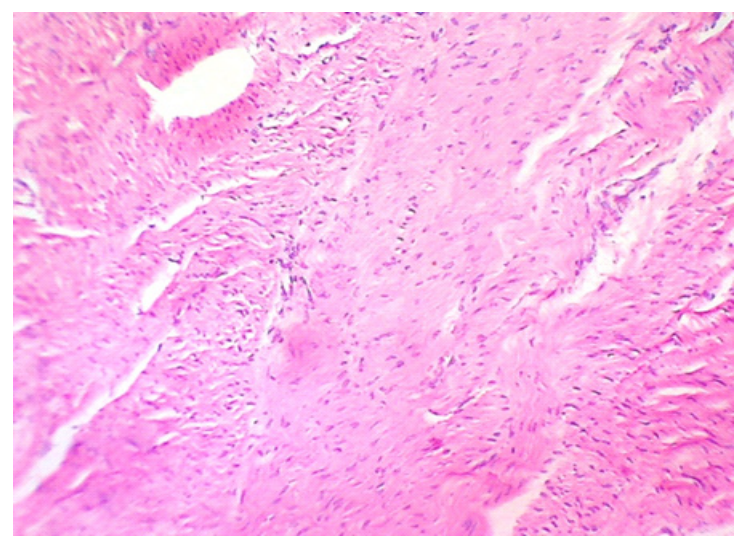

Fig.16. Histological section of tendon healing in the 3rd group, two months post-surgery. The collagen fiber appeared organized, edema between collagen fibers without any inflammatory reaction. $H \& E, 100 x$. 


\section{Discussion}

In dogs, rupture of the Achilles tendon due to chronic overstretching, sharp cutting or laceration is one of the most common tendon injuries, which require surgical intervention [17]. The severity of tendon rapture varies from complete rupture (26.7- 42.8\%), partial (22.2\%) or isolated rupture of the gastrocnemius tendon (20\%) [16]. In dogs, many synthetic and natural implants were utilized successfully to repair defective tendons, such as carbon fiber, polypropylene mesh and autogenous flaps, including free fascia lata grafts. Similarly, several works were conducted in rabbits to examine the efficiency of autogenous omental graft in stimulating the collagen formation $[19,20]$. It has determined that the ideal postoperative outcome of restoration the functional role of tendons characterized by an appropriate tension and strength to overcome the dynamic workload [20]. In the current work, unlike traditional suturing, only Kessler suture technique was used along with autogenous vein graft to support the ruptured tendon. The utilizing of autologous peritoneum as a bioscaffold manifested an apparently good, hasted and improved tendon healing. These results may be approved that, in a dogs model, peritoneum graft can be used for tissue engineering. In all groups, there were signs of lameness ranged from mild to moderate, which might result in manipulation of the tendon during surgery, incomplete intact of tendon tissue, or due to the inflammatory reaction; However, these signs were subsided gradually with time; similar signs were reported in previous works [21,22]. In the second group, gross examination revealed that the peritoneum patch subsided after 15 days of surgery without any inflammatory reactions. Nevertheless, a previous study conducted on rabbits, the using of scaffold products like small intestine submucosal tissue (SIS), the inflammatory reaction extended from the early days after surgery until the next two months where absorption of the implant occur [23]. It has determined that adhesion is the most common side effect after tendon surgery [19]. In our study, the occurrence of adhesion between the tendon and neighboring tissue was high, especially in the first group. The using of peritoneum and vein graft manifested lowered the incidence of adhesion. This might be attributed to the biological properties of these materials, which acts as a protective shield against adhesions and supports the healing process of the tendon. These results agreed with a previous report on using SIS
[24]. The using of peritoneum and vein graft may support tendon healing by overcoming the devitalization of the tendon due to ischemic damage results in multiple suture stitches [25].The success repairing of an injured tendon is a challenging issue because of the tension during muscle contraction; however, in our work, there was a good outcome of using the peritoneum and vein grafts. These materials provide excellent support to the injured tendon, reduce the likelihood of gap formation, offer a perfect suturing space, and maintain the gliding movement of the tendon. These observations were previously recorded by another work [26]. Whereas in the first group, several dogs expressed poor clinical outcomes and delayed tendon healing, this might occur due to poor suture holding. The using of jugular vein autography improved the healing process through increasing the fibroblastic proliferation and by reducing the degree of adhesion, these results agreed with [27]. In the $1^{\text {st }}$ group, results obtained from the histological examination revealed the presence of severe inflammatory reaction after 15 days post-surgery. The inflammatory reaction was subsided gradually at the second 60 days, where only signs of a mild inflammatory reaction were identified. Conversely, in the $2^{\text {nd }}$ and $3^{\text {rd }}$ groups, the severity of detectable inflammatory signs was lighter than in the first group after 15 and 30 days. Interestingly, these signs were unnoticeable after 60 days. This finding agreed with other studies and might be explained by the way that degradation of extracellular matrix scaffolds products has some antibacterial properties. Reversely, if degradation does not occur, the extracellular matrix scaffolds increases the bacterial growth [11]. Additionally, by comparison between the control and treated groups after 30 and 60 days post operation, it has demonstrated that treatment with grafts enhanced the healing process. This variation in response in treatment might be attributed to the biological components of these two grafts including collagen, glycoprotein, and growth factors. The collagenous component in the resorbable materials was successfully used in xenograft, autograft, and allograft purposes in various tissues and organs in animal models [11]. These studies have pointed out that these biomaterials can support the growth of the host tissue, increase cellular differentiation and induces a site-specific remodeling for several kinds of connective tissues. The regenerative process leads to re-establish both the mechanical functional of tendon and structural properties similar to the original tissue [28]. Based on

Egypt. J. Vet. Sci. Vol. 50, No. 2 (2019) 
previous research, vein graft acts as a source of cellular elements for producing a various number of growth factors responsible for acceleration tendon healing [27]. Results of peritoneum treated group manifested a faster healing than in other groups, which was evident by a complete granulation tissue formation and the presence of a low number of fibroblast count. Thus, we concluded that the using of autogenous peritoneal grafts peritoneum patches could successfully improve tendon healing and reducing the degree of adhesion.

\section{Conclusion}

In conclusion, results exhibited from the using of peritoneal graft for repairing tendon defect was with the most beneficial and efficient outcomes.

\section{Acknowledgments}

We would like to thank the assistant professor Dr. Hana Ismail dep. of pathology,Mosul,Iraq. for her support with the histopathological examination. In addition, we would like to emphasize our appreciation to our colleague Dr. Isam Sharum,Mosul,Iraq. For his support.

\section{References}

1. James, R., Kesturu, G., Balian, G., Tendon biology, biomechanism repair growth factor evolving treatment option. Journal of hand surgery, 33, 102-112 (2008).

2. Young, M., Stem cell applications in tendon disorders: a clinical perspective. Stem Cells., 1-10 (2012).

3. Dal-Bó, C.R., Ferrigno, A.S., Macedo, et al., Tenorrhaphy of the Common Calcaneal Tendon in Dogs and Cats. Acta Scientiae Veterinariae., 44, 144 (2016).

4. Baltzer, W.I., Rist, P., Achilles tendon repair in dogs using the semitendinosus muscle: surgical technique and short-term outcome in five dogs. Vet Surg., 38, 6, 770-779 ( 2009).

5. Ambrosius, L., Arnoldy, C., Waller, K.R., Little J.P, Bleedorn, J.A., Reconstruction of chronic triceps tendon avulsion using synthetic mesh graft in a dog. Vet Comp OrthopTraumatol., 28, 3, 220224 (2015).

6. Amin, B., Mehran, A., Effat, K., Iraj, K., and Ahmad, O., Tendon injury healing with G-90 in a rabbit model: biomechanical and histopathological evaluation. Veterinarski Archive., 86, 3,407-420 (2016).

7. Hayder, H. and Thaier, A.,. The effect of lowlevel laser therapy on tendon healing in male rats. AL-Qadisiya Journal of Vet. Med. Sci., 14, 2,101(2015)

8. Fahi, M.A., Healing diagnosis,repair and rehabitation of tendon condition. Veterinary Clinic Small Animal Practice., 35, 1195-1211 (2005)

9. Ferrara, N., Role of vascular endothelial growth factor in physiologic and pathologic angiogenesis. Therapeutic implication. Semin. Oncol ., 29, 10-14 (2002).

10. Joseph, J., Albano, M.D. And Robert W., Autologous fat grafting as a mesenchymal stem cell source and living bioscaffold in patellar tendon tear. Clinic J. sport., 21, 359-363. (2011)

11. Jahani, S., Moslemi, H.R., Dehghan, M.M., Sedaghat, R., Mazaheri, R.N, and Moghaddam, D.R., The effect of butyric acid with autogenousomental graft on the healing of experimental Achilles tendon injury in rabbits. Iranian Journal of Veterinary Research, Shiraz University., 16 (1), 100-104 (2015).

12. Guarino, V., Causa, F., Ambrosio, L., Bioactive scaffold for bone and ligament tissue. Expert Review of Medical Devices., 4, 405-418 (2007).

13. Stavrou, M., Treatment for Achilles tendon ruptures in athletes. Ortho. Journal of Bone and Joint Surgery., 21,232 (2013).

14. Mario, K., Josip, K., Snježana, V., Dražen, V., Dražen, M., Boris, P., Marko, S., Marko, P., Ozren, S., Petar, K., and Mirna, A., Influence of suture material on biomechanical and histological indicators of Achilles tendon healing in rabbits. Veterinarski Arhiv., 81, 2, 223-233 (2011).

15. Luna, L.G., Manual of Histological Staining Methods of the Army Forces Institute of Pathology Division $3^{\text {rd }}$ ed. New York, USA, McGraw Hill Book Company. 12-20. (1968)

16. Suvarna, S.K., Layton, C., Bancroft, J.D., Bancroft's Theory and Practice of Histological Techniques.7th ed New York USA: Churchill Livingstone Press., 20, 12-32 (2013).

17. Schultz, K., Management of muscle and tendon injury or disease. In: Fossum TW, ed. Textbook of Small Animal Surgery. $4^{\text {th }}$ ed. St. Louis, MO, Mosby, 1375-1390 (2013).

Egypt. J. Vet. Sci. Vol. 50, No. 2 (2019) 
18. Corr, S., Draffan, D., Kulendra, E., Carmichael, S., Brodbelt, D., Retrospective study of Achilles mechanism disruption in 45 dogs. Vet. Rec., 167, 407-411 ( 2010)

19. Wendy, B.,.Treating tendon and ligament injuries in dogs--from surgery to platelet-rich plasma to laser therapy (Proceedings). (2011)

20. Spinella1, G., Tamburro, R., Loprete, G., et al. Surgical repair of Achilles tendon rupture in dogs: a review of the literature, a case report and new perspectives. Veterinarni Medicina, 55 (7), 303$310(2010)$

21. Sacks, M.S, Cloeckner, D.C., Quantification of the fiber architecture and biaxial mechanical behavior of porcine intestinal submucosa. J Biomed Mater Res., 46, 1-10 (1999).

22. Alkattan, L.M., Mohammed, F.M., Bader, O.A., Repairing of transversely cutting Achilles tendon with autogenous intestinal submucosal layer in dogs Bas. J. Vet. Res., 12 (2), 56 (2013)

23. Malcarney, H.L., Bonar, F., Murrell, G.A., Early inflammatory reaction after rotator cuff repair with a porcine small intestine submucosal implant: a report of 4 cases. Am. J. Sports. Med., 33, 907-911 (2005)

24. Fernando, H.G., Eduardo, J.B. Vanessa, C.D., Antonio, P.G., Wilson, H.M. and Luciano, O., Evaluation of porcine small intestinal submucosa in Achilles tendon repair. Journal of Applied Research, 5 (1), 212-217 (2005)

25. Stein, L.E., Pijanowski, G.J., Johnson, A.L., A histological evaluation of rabbit tendons sutured using the Bunnell pattern. Vet Surg., 14, 145-148 (1985)

26. James, R., Kesturu, G., Balian, G., Chhabra, A.B., Tendon: biology, biomechanics, repair, growth factors, and evolving treatment options. Journal of Hand Surgery, 33, 102-112 (2008)

27. Daradka, M.H., Malkawi, M.A., Ismail, Z.B. and Alshehabat, M.A., Autologous venous grafting promotes healing and reduces adhesion formation in experimentally severed canine superficial digital flexor tendons. Bulgarian Journal of Veterinary Medicine, 19 (3), 233-241 (2016)

28. Greca, F.C., Ramos, E.J., Dallolmo, V.C. and et al., Evaluation of Porcine Small Intestinal Submucosa in Achilles Tendon Repair. The Journal of Applied Research, 5 (1), 115-123 (2005).
29. Mohamed, A. Hamed, Khaled, S. Abouelnasr, Mohamed, El-Adl, Eman, A. Abo Elfadl, Amany Farag, Samah Lashen. Effectiveness of Allogeneic Platelet-Rich Fibrin on Second-Intention Wound Healing of Experimental Skin Defect in Distal Limb in Donkeys (Equus asinus). Journal of Equine Veterinary Science, 73, 131-138 (2019).

30. Green, S. and Thurmon, J.C. Xylazine a review of its pharmacology and use in vet medicine $J$. Vet. pharmacoltherap, 11, 295-313 (1988) 


\title{
تقييم مقارن لاور سقالات الرقع الذاتيه من الوريد والبريتون لاصلاح ضرر وتر اكيل في \\ الكلاب

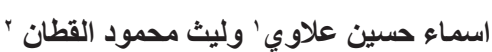

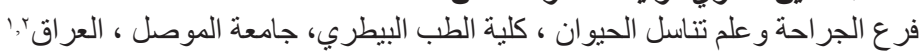

\begin{abstract}
اجريت الدر اسة على ثمانية عشر كلبا سليما تم تقسيمها الى ثلاثة مجاميع متساويه (ست كلاب في كل مجمو عةثة).

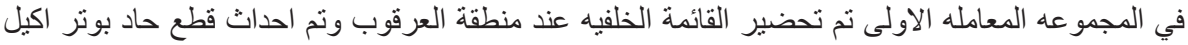

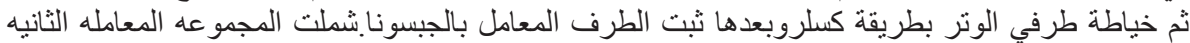

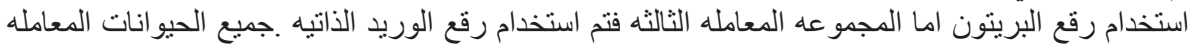

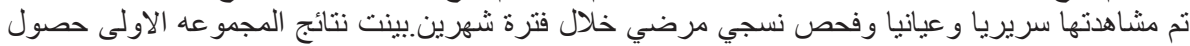

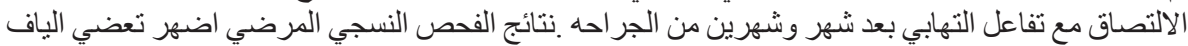

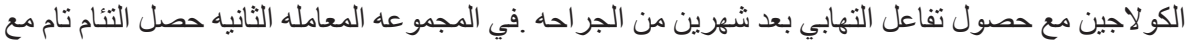

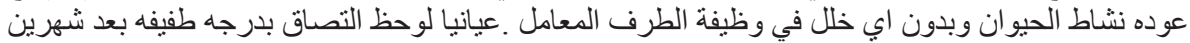

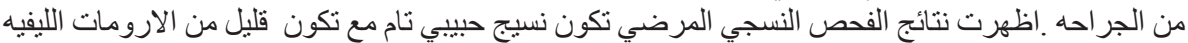

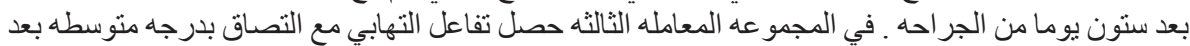

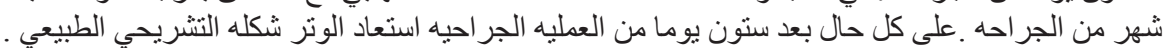

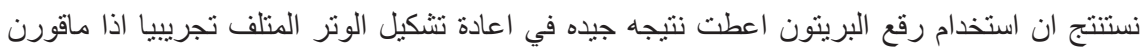

بالمجاميع المعامله الاخرى و هذا يعتبرمن العلامات الجديده في علاج الونت التئ المتلف. 